\section{The history of commonly used dental elevators}

\author{
M. A. Bussell ${ }^{1}$ and R. M. Graham²
}

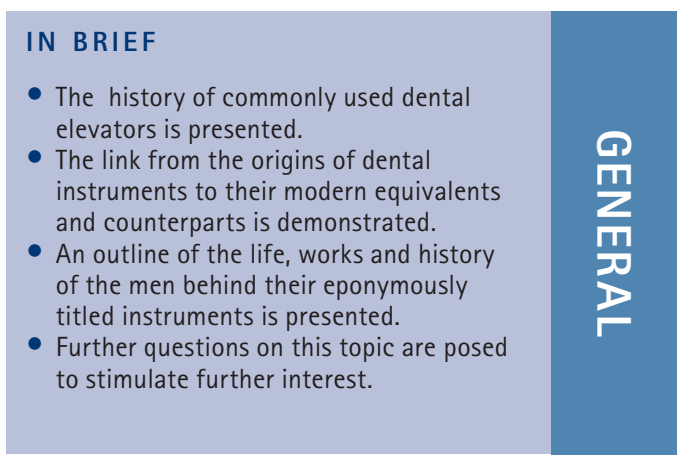

Despite the extensive and regular use of dental elevators on a daily basis in both general dental and specialist oral and maxillofacial surgical practice, little is known about the history and origins of such instruments and this remains an intriguing question. This question has been the basis for the following article, which gives a brief history of the instruments, discusses their eponymous origins and the history, life and works of the individuals they are named after. In-depth research has also raised other questions about such instruments that could be the focus for further study.

\section{Introduction}

Dental elevators are well-established dental instruments and are frequently used for oral surgical procedures ranging from routine dental extractions to more complex surgical procedures performed by oral and maxillofacial surgeons. Elevators have served the profession well for many centuries and have endured the test of time. Like most instruments, they have evolved, taking on a variety of shapes, names and materials.

In the early days of performing dental extractions; expediency was an important factor in the evolution of extraction instruments. Prior to the introduction of analgesics and anaesthetics, in theory, the quicker the tooth could be removed the less pain would be inflicted on the patient., ${ }^{1,2}$

The first drawings of elevators date back to 1122, in the work of Albucasis ${ }^{3}$ or Abulcasis. ${ }^{4}$ Early elevators were referred to as 'punches' ('repoussoirs') or 'levers'

\footnotetext{
${ }^{1 *}$ Clinical Dental Officer, Oldham Primary Care Trust, Cannon Street Health Centre, Cannon Street, Oldham, OL9 6EP; ${ }^{2}$ Specialist Registrar, Department of Oral and Maxillofacial Surgery, North Manchester General Hospital, Delaunay's Road, Crumpsall, Manchester, M8 5RB ${ }^{*}$ Correspondence to: Mary A. Bussell Email: maryalicebussell@ hotmail.com
}

\section{Refereed Paper}

Accepted 4 September 2008

DOI: $10.1038 /$ sj.bdj.2008.933

${ }^{\circledR}$ British Dental Journal 2008; 205: 505-508

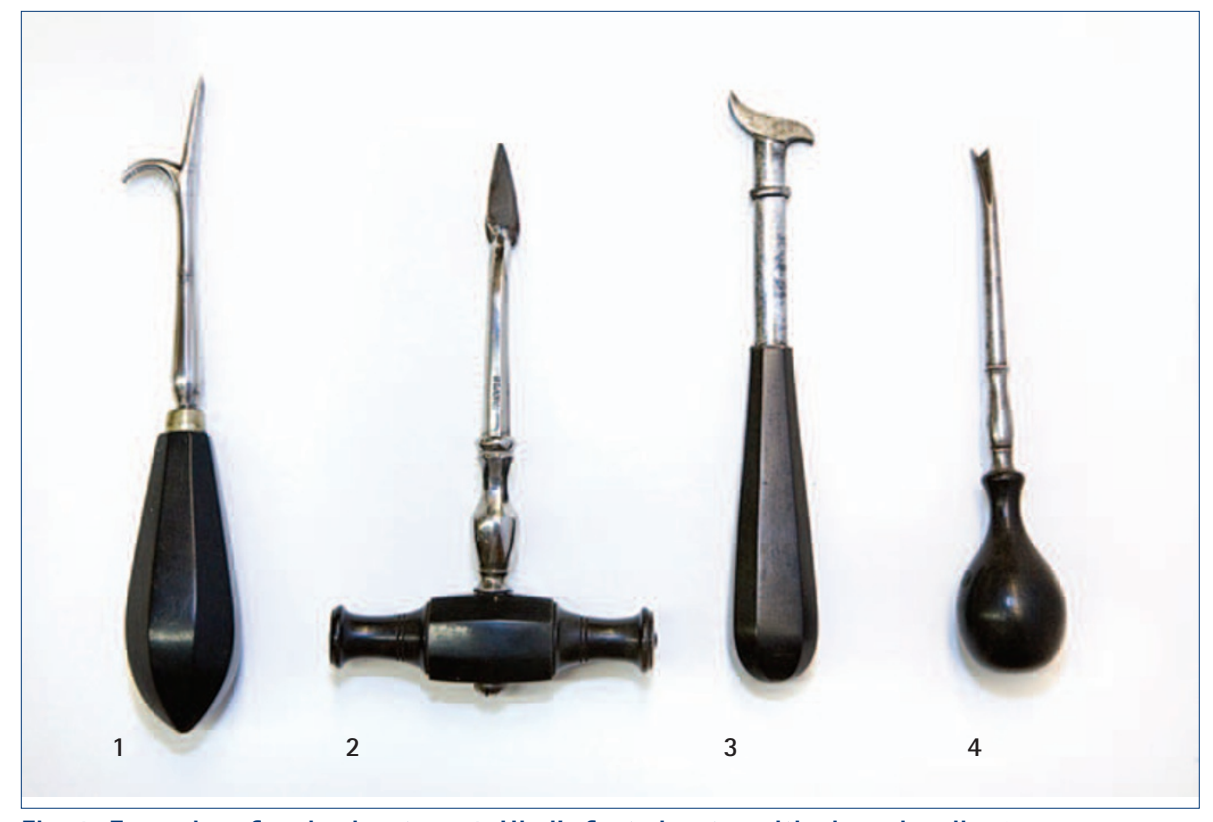

Fig. 1 Examples of early elevators: 1. Hind's foot elevator with ebony handle; 2. Spade-shaped elevator c1800-1810, made by French instrument maker Blanu; 3. Punch elevator with ebony handle c1795; 4. Goat's foot elevator with ebony handle. Reproduction by courtesy of the British Dental Association

and can be dated back to the 16th century. $^{3}$ An example of an early elevator is 'The Expluser', which was used at the end of the 16th century. ${ }^{5}$ Another example is the 'Geissfuss' (goat's foot), so called because of its appearance (Fig. 1), and a variant of this was the 'Geissfuss mit Haken' (goat's foot with a claw). ${ }^{3}$

In 1754, Lecluse introduced an elevator $^{4}$ and some believed this design to be curved. ${ }^{3}$ The latter is likely to be very similar to some of the elevators that are in use today. Commonly used curved elevators nowadays include those eponymously titled as Warwick James and Cryer's elevators.

Thomas Bell (1792-1880) is thought to have introduced the use of elevators into general dental practice ${ }^{6}$ and he preferred to use elevators for the removal of lower third molars. ${ }^{3}$

The choice of material for manufacture of dental elevators has also evolved; early dental instruments were made of iron $^{3,6}$ or brass. ${ }^{6}$ Elevators used during the 18th and 19th centuries had handles 
of ivory or ebony, ${ }^{1,3,6}$ as can be seen in the example in Figure 1. Over recent years, the awareness of cross infection control and the introduction of methods of sterilisation including the use of steam has influenced the materials used; currently used elevators are made of stainless steel. 5

This article aims to provide the story behind modern dental elevators in use today and the men that they are named after.

\section{William Warwick James}

William Warwick James (Fig. 2) lived from 1874 to 1965 and was said to be one of the most inspiring and outstanding dental surgeons of his time. ${ }^{7,8}$ He was born in Wellingborough, Northamptonshire, ${ }^{7,9,10}$ and attended the Royal Dental and Middlesex Hospital schools., ${ }^{7,810}$ He obtained both dental and medical qualifying diplomas in $1902^{7}$ and undoubtedly laid the foundation for double degree status for future generations of oral and maxillofacial surgeons. In 1905 he obtained the FRCS (England). ${ }^{7,9,10}$ He worked at the Royal Dental and Middlesex Hospitals and the Hospital for Sick Children at Great Ormond Street, London. ${ }^{7-9}$ He also continued to work in dental practice throughout his career. ${ }^{8}$

Warwick James' passion from early in his career and throughout, even beyond retirement from clinical practice, was research. $^{7,10}$ He co-authored several important papers of the day on subjects such as odontomes (a classification of these was developed and used for many years afterwards), dental cysts, caries, bleeding related to extractions and facial fractures, mouth breathing and pyorrhoea alveolaris ${ }^{7,8,10}$ - the latter a precursor to future work on periodontal disease. In 1923 he obtained the Tomes prize (RCS England). ${ }^{7,9}$

During and after the First World War he worked with the maxillofacial unit at the Third London General Hospital where he repaired many extensive facial injuries and received an OBE for services to Queen and country., ${ }^{7,8}$ This was before the establishment of the special maxillofacial unit at Sidcup ${ }^{8}$ and he developed new methods for the treatment of severe facial wounds. ${ }^{8}$ In 1940 he co-authored

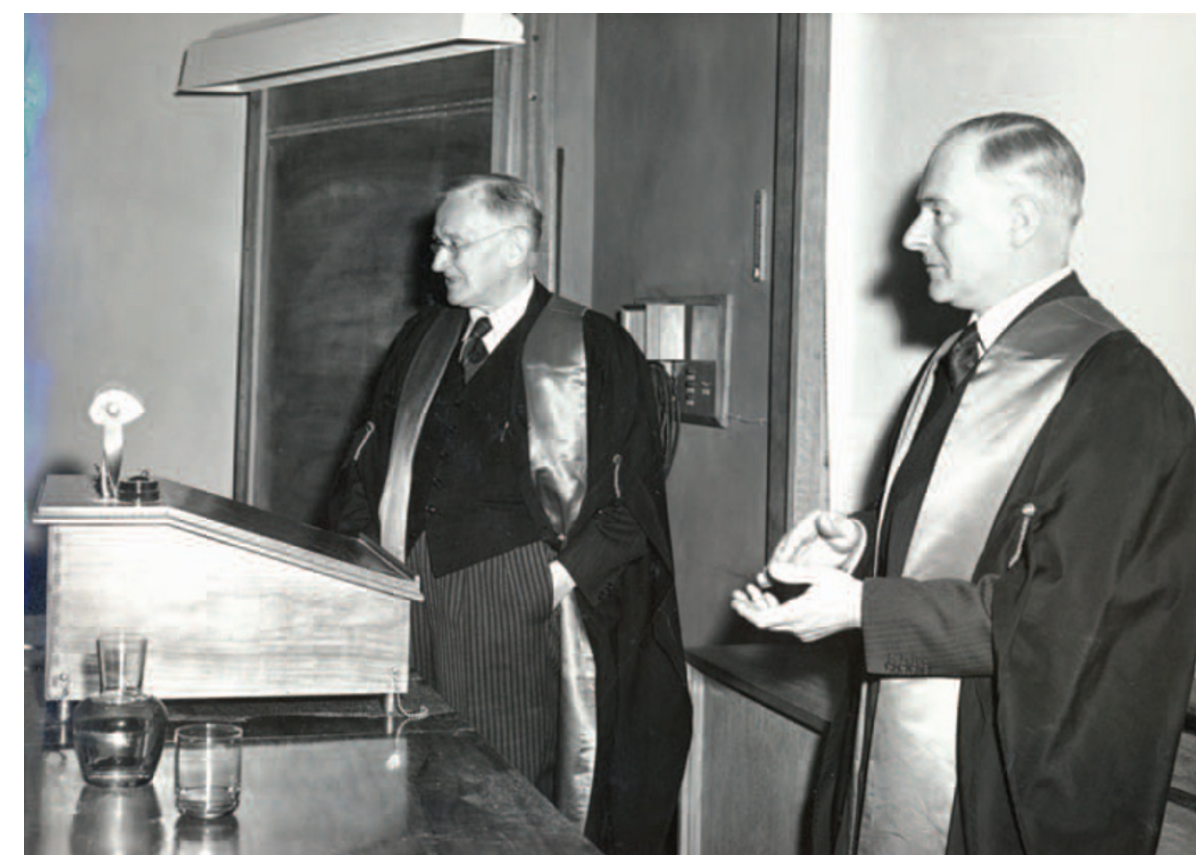

Fig. 2 William Warwick James, on the left with Benjamin W. Fickling. Taken 31 October 1961 at a lecture given by William Warwick James to the Royal Dental Hospital. Reproduction by courtesy of the British Dental Association

an authoritative text of the day with Benjamin W. Fickling, entitled Injuries to the face and jaws with special reference to war casualties, the source materials for which were his own notes and records, as official records at Sidcup and Aldershot were destroyed during the First World War. ${ }^{8,10}$ It is interesting to note that Warwick James performed facial and dental operations before the days of endotracheal intubation and antibiotics. ${ }^{8}$

In later life he was awarded an honorary MCh from Birmingham University for outstanding contributions and continued research into areas such as comparative anatomy and palaeontology.-9 He encouraged others to pursue research, developed a research fund and had an eponymous lecture founded in his honour at the Royal Dental Hospital School in $1962 . .^{7,8}$

\section{Matthew Henry Cryer}

Matthew Henry Cryer (Fig. 3) was born in Manchester, UK on 11 July $1840 .{ }^{11}$ As a child, he moved with his family to America and it is in the state of Pennsylvania that Cryer is remembered for his many contributions to dentistry and in particular oral surgery.

In 1874, Cryer began his studies at the Philadelphia Dental College; he received a DDS degree two years later and then an

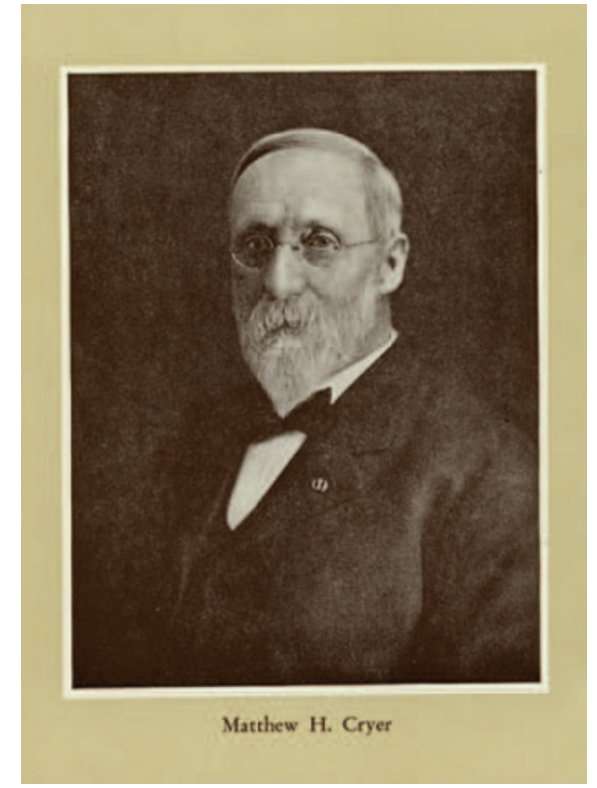

Fig. 3 Matthew H. Cryer (1840-1921). Image reproduced from Historical Collections \&t Archives, Oregon Health at Science University

MD degree from the University in 1877. Following graduation, Cryer remained at the Philadelphia Dental College as a lecturer in mechanical dentistry. ${ }^{11} \mathrm{He}$ spent 17 years working in the Hospital of Oral Surgery, following which he was promoted to Assistant Professor of Oral Surgery in $1897 .{ }^{11}$ In 1901, Cryer founded the first hospital dental service in America, at the Philadelphia General Hospital. ${ }^{12}$ 
Cryer had a great interest in anatomy and his expertise in the anatomy of the face and cranium was renowned nationwide. He wrote several anatomical textbooks, including Studies of internal anatomy of the face (1901, 2nd ed 1916). ${ }^{11,12}$ Cryer's collection of specimens and skulls is thought to be one of the largest and most complete in existence and today it can be found in the Mutter Museum of the College of Physicians, Philadelphia. ${ }^{11}$

His contributions to oral and craniomaxillofacial surgery include the development of the electrically operated surgical engine for cutting bone $\mathrm{e}^{5,12}$ and the spiral osteotome and guard for cranial surgery. ${ }^{11}$ He used the surgical engine while performing jaw surgery and exposing embedded teeth. ${ }^{5}$ The surgical engine, along with new developments in dental radiography and local anaesthetics, increased the practice of surgical procedures in dentistry.

Cryer died on 12 August 1921. His name in dentistry and oral surgery will not be forgotten as he played an important role in the development of oral surgery in the United States of America ${ }^{12}$ and his contributions to dental surgery have made a lasting impression. Several societies and prizes have been created in his honour.

\section{Their elevators}

William Warwick James is essentially remembered nowadays because of his eponymous association with a set of three elevators (straight, right and left curved) (Fig. 4). It is thought that the origin of his elevators was the Thompson's curved elevator, and that Sir William Kelsey Fry (1889-1963) popularised their use. ${ }^{4,13}$ What is curious and somewhat contradictory is that despite having oral surgical instruments named after him, it is reported that Warwick James disliked elevators. ${ }^{14}$ This is because of the need for a fulcrum, which can compress alveolar bone, and he believed this to be the source of osteitis and postoperative pain. ${ }^{8}$ He preferred to extract teeth with Read's upper forceps, even wisdom teeth, for which he also used a lingual approach. ${ }^{8}$ This approach, which he in fact used both as a tooth

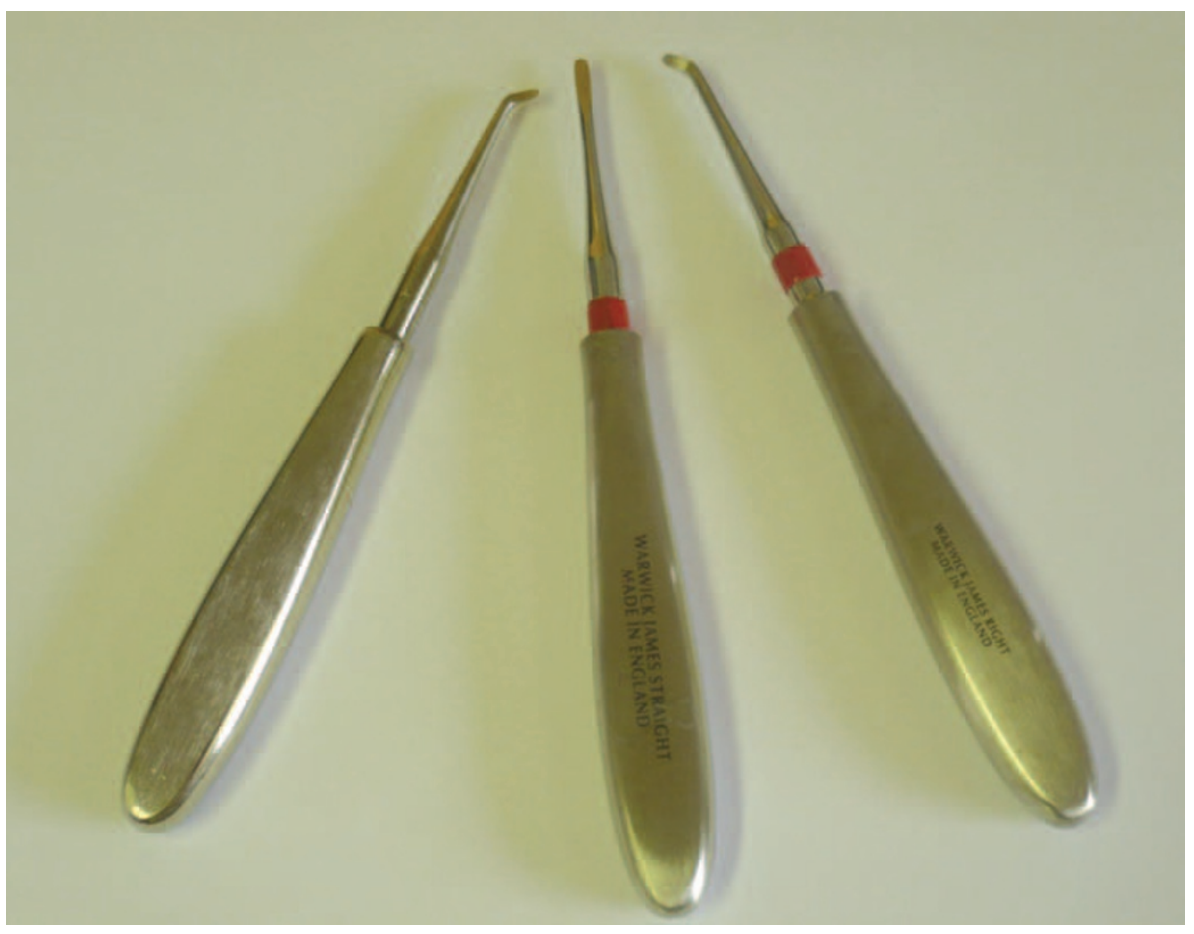

Fig. 4 Straight, right and left Warwick James elevators

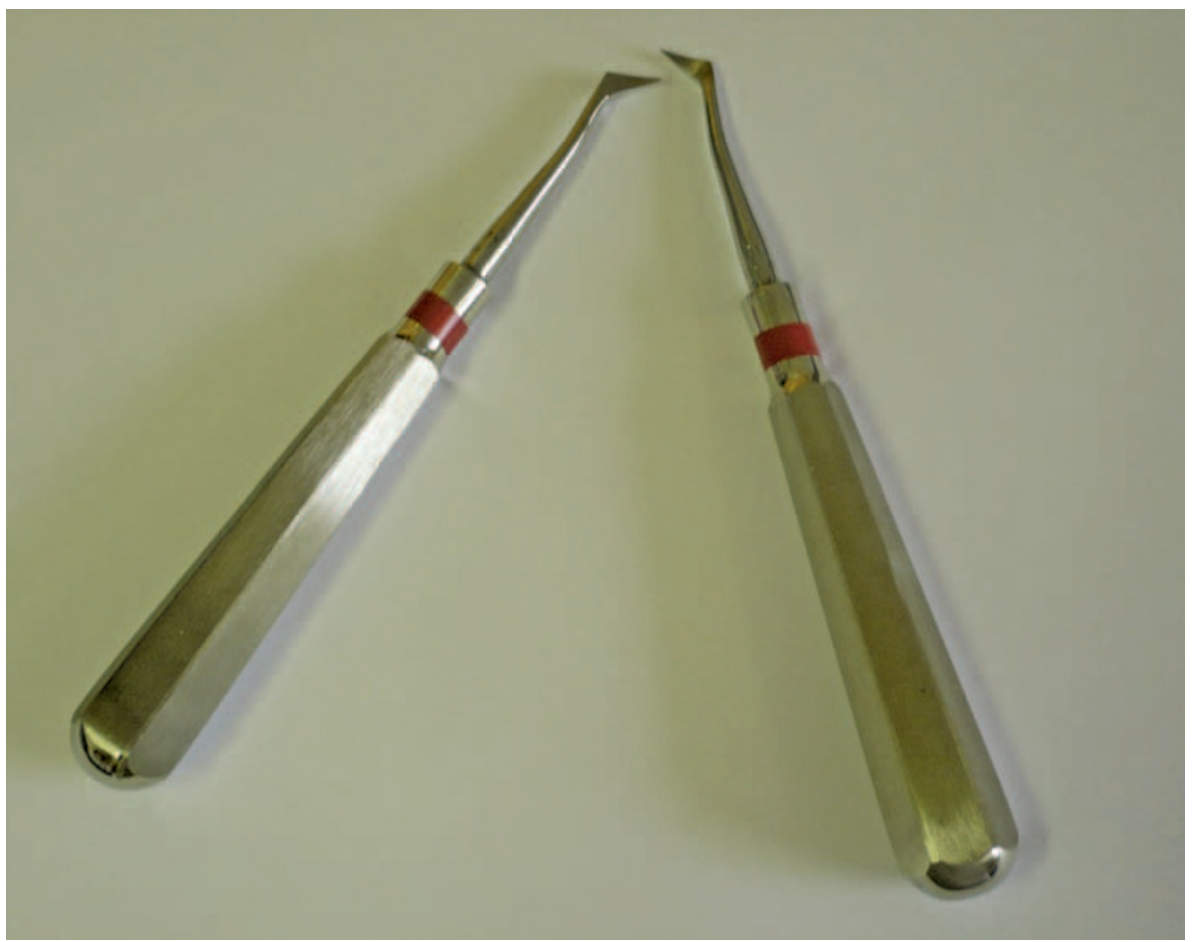

Fig. 5 Right and left Cryer's elevators

mobilisation and drainage procedure, is likely to have been a forerunner to the lingual split technique. ${ }^{8,14}$

Matthew H. Cryer made several notable contributions to the development of surgical dentistry. At the beginning of the 20th Century (1904), he designed a pair of universal incisor and root forceps, ${ }^{11}$ one for upper teeth and one for lower teeth. ${ }^{5}$ He believed that these two forceps could be used to extract any tooth in the mouth. ${ }^{11}$ It is stated that Cryer was also responsible for the greatly increased use of elevators. ${ }^{11} \mathrm{He}$ made a pair of left and right scaling instruments heavier (originally known as SSW scalers, probably from the S. S. White Dental Manufacturing Company), ${ }^{4}$ which he was then able to use to elevate dental roots. ${ }^{11}$ The left and right elevators bearing his name were thus developed (Fig. 5). 


\section{Coupland(s)} and yet remain perplexed as to the origins of the Coupland(s) elevators (or possibly chisels). ${ }^{4}$ A thorough World Wide Web-based search and also searches in several libraries have not revealed any relevant information. Perhaps most confusingly, the Manchester/Turner Dental Hospital and School is in close proximity to Coupland Street and also the Coupland 3 building. However, the authors have been assured by several sources that this is merely a coincidence.

If anyone reading this article is able to provide any information on Coupland(s) and the origins of the Coupland(s) elevators, the authors would be most interested to learn the answer.

\section{Conclusion}

Dental elevators were first designed many years ago and are still in regular use today. The use of elevators has remained the same, to assist in or indeed
The authors have gone to great lengths

perform alone the removal of a tooth or root. An early surgeon, Sir John Tomes. quoted 'There is scarcely a root, or even a tooth which cannot be removed by the elevator. ${ }^{5}$

Elevators have been modified on many occasions to make their use more efficient and ergonomic. From the evidence provided there would seem to be a clear link between modern elevators and early documented elevator-type instruments, both in terms of design and materials used.

This article has given a very brief history of dental elevators and discussed only a few. The list of elevators currently available to purchase is extensive (see footnote).* These could potentially be the focus of a future research project.

The authors acknowledge the kind assistance of: Mr M. E. Foster, Consultant Oral and Maxillofacial Surgeon, North Manchester General Hospital; the late Professor John C. Lowry, Consultant Oral and Maxillofacial Surgeon, Bolton; Melanie Parker, Museum Education Officer, BDA; Sally Dummer, Acting Head of Museum Services, BDA staff at the John Rylands Library, University of

*Lecluse root elevator, Winter root elevator, Mead root elevator, Walter F. Barry root elevator, Pott root elevator, Apical root elevator, Seldin root elevator, Flohr root elevators, Crane root elevators, Miller root elevator, Hylin root elevator, Friedman root elevator, Bein root elevator, Ratzow root elevator, Berlin root elevators, Heidbrink root elevators, Lindo-Levien root elevators, Coleman root elevators, White root elevators, Schlemmer root elevators, Read root elevators, Thomson root elevators, Spear dental root elevators, Trauner root elevators, Berten root elevators, Bertrand root elevators, Heylin root elevators, Pique root elevators, Krallenheber dental elevators, Kopp root elevators, Fifo root elevators, Septum Lancet's root elevators, Gardner root elevators. 15,16
Manchester; The Wellcome Library, London; and the Libraries of RCS England, Edinburgh and Glasgow.

1. Atkinson H F. Some early dental extraction instruments including the pelican, bird or axe? Aust Dent 12002; 47: 90-93.

2. Dummer S. Instrument Darwinism. BDA News 2008; 21(5): 22.

3. Colyer F. Old instruments used for extracting teeth London: Staples Press Ltd, 1952.

4. Findlay I A. The classification of dental elevators. BrDent J 1960: 109: 219-223.

5. Glenner R A. Dental office: a pictorial history. Pictorial Histories Publishing Co., 1984.

6. Bennion E. Antique dental instruments. London: Philip Wilson Publishers Ltd, 1986.

7. Anon. In memoriam W. Warwick James (18741965). Ann R Coll Surg Eng/ 1965; 37: 318-319.

8. Fickling B W, Boyes J. 'No end to talk about'. Personal recollections of the late William Warwick James. Br Dent J 1975; 138: 181-187.

9. Anon. William Warwick James. Lancet 1965; 286: 644-645.

10. Fickling B W. William Warwick James. Br Dent J 1965; 119: 326-327.

11. Asbell M B. A century of dentistry. A history of the University of Pennsylvannia School of Dental Medicine, 1878-1978. Philadelphia: University of Pennsylvania Press, 1977.

12. Archer W H, Irby W B, Asbell M B. The history of the development of anesthesia, oral surgery and hospital dental service in the United States of America. Pittsburgh, 1971. Reprinted from: Oral surgery directory of the world. 4th ed, 1971.

13. Anon. In memoriam: Sir William Kelsey Fry. Ann $R$ Coll Surg Engl 1963: 33: 390-392.

14. Warwick James W. An improved procedure for the removal of impacted third mandibular molars. Proc $R$ Soc Med 1935; 29(2): 85-87.

15. Medical Tools website. Dental root elevators webpage. http://medical-tools.com/dental_root_ elevators1.html (accessed 10 0ctober 2008).

16. AA Instruments website. Root elevators webpage. http://www.aainstruments.com/dental/elevators/ rootel1.htm (accessed 10 October 2008). 